Supplement of The Cryosphere, 15, 2575-2591, 2021

https://doi.org/10.5194/tc-15-2575-2021-supplement

(C) Author(s) 2021. CC BY 4.0 License.

(c) (i)

Supplement of

\title{
Interannual variability in Transpolar Drift summer sea ice thickness and potential impact of Atlantification
}

\section{H. Jakob Belter et al.}

Correspondence to: H. Jakob Belter (jakob.belter@awi.de)

The copyright of individual parts of the supplement might differ from the article licence. 


\section{Supplements}
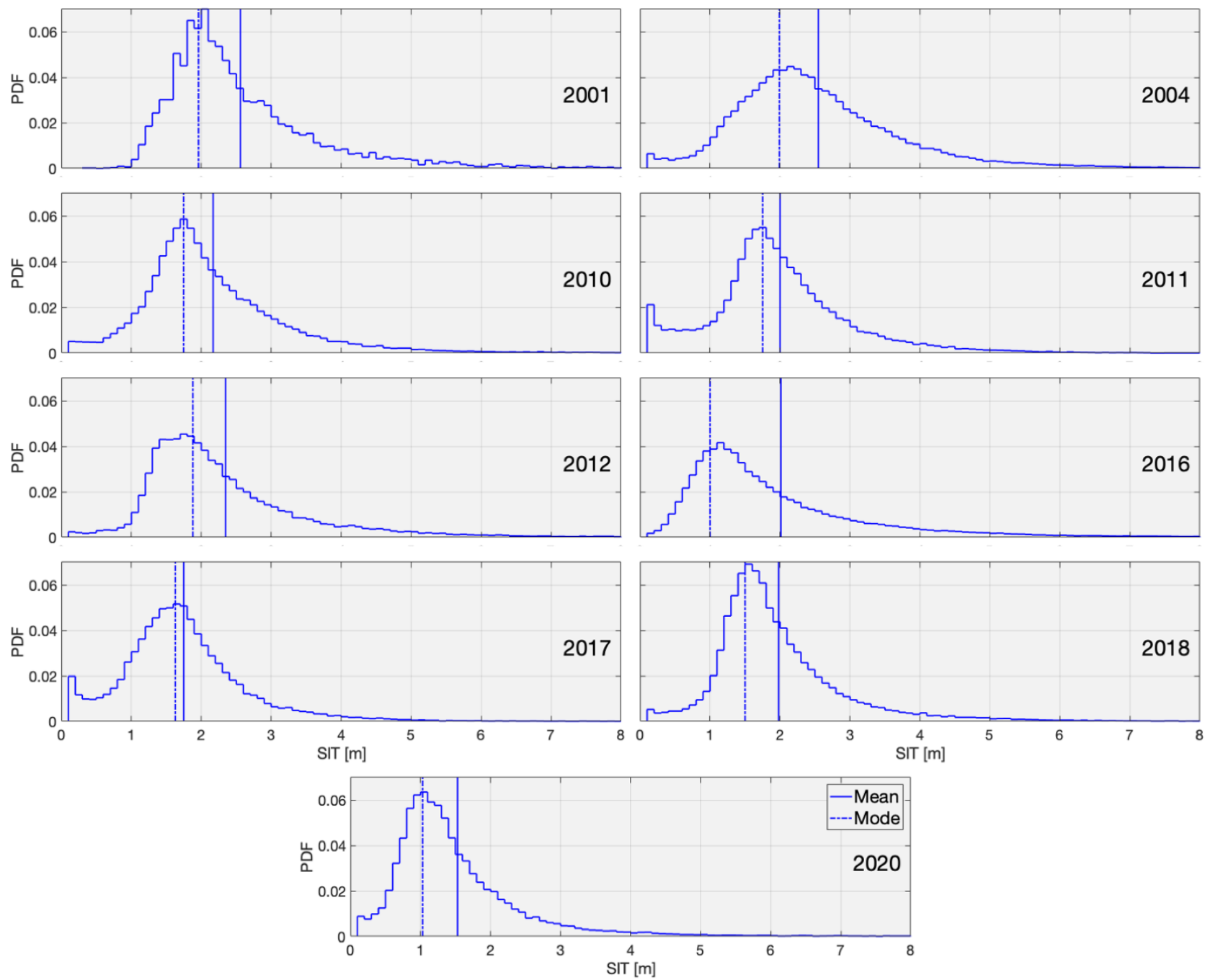

Figure S1. Distributions of measured EM SIT values in the AOI between 2001 and 2020. Vertical lines of mean (solid) and modal (dashed) EM SIT correspond to AOI mean and modal values shown in Fig. 1 b). 2020 distribution is based on airborne measurements (filled circles in Fig. 1 b)). The 2020 distribution based on ground-based (GEM) measurements (diamond in Fig. 1 b)) is given in Fig. S5 (black). 


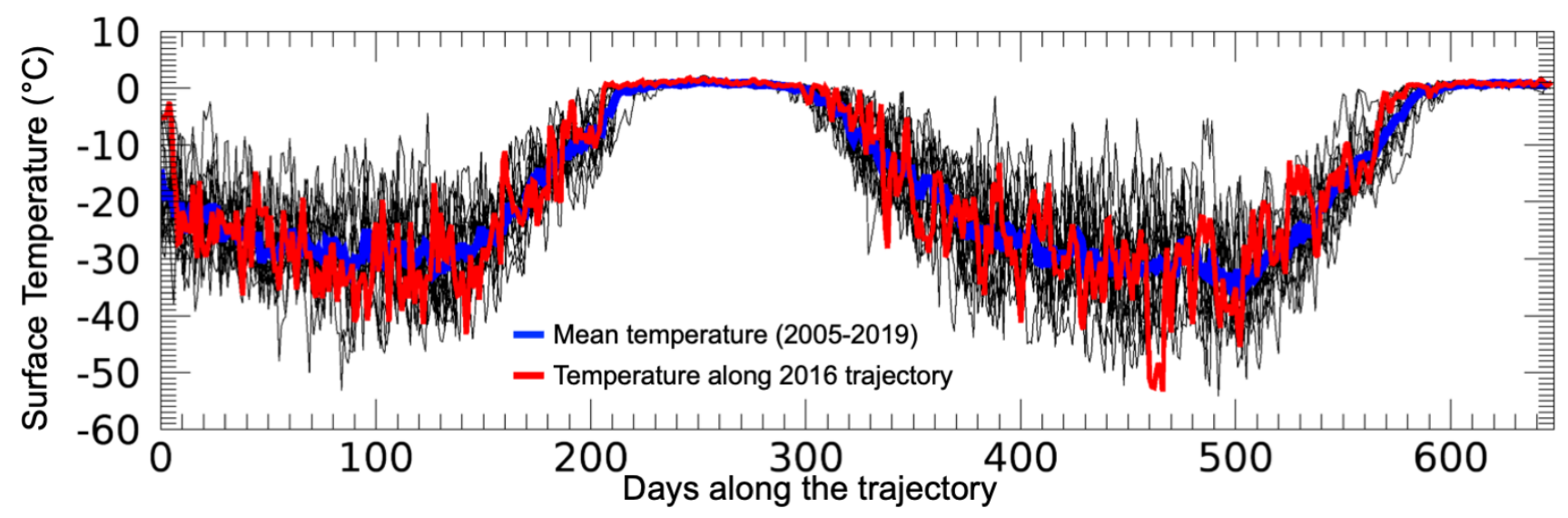

Figure S2. Daily surface air temperatures (NCEP/NCAR re-analysis Kalnay et al., 1996) along the trajectory (day 1: ice formation, day 650: end of trajectory in the AOI) of the ice sampled in the AOI in 2016 (red line) and along the same trajectory for the years from 2005 to 2019 (black lines). The average along the trajectory for the period from 2005 to 2019 is given by the blue line.

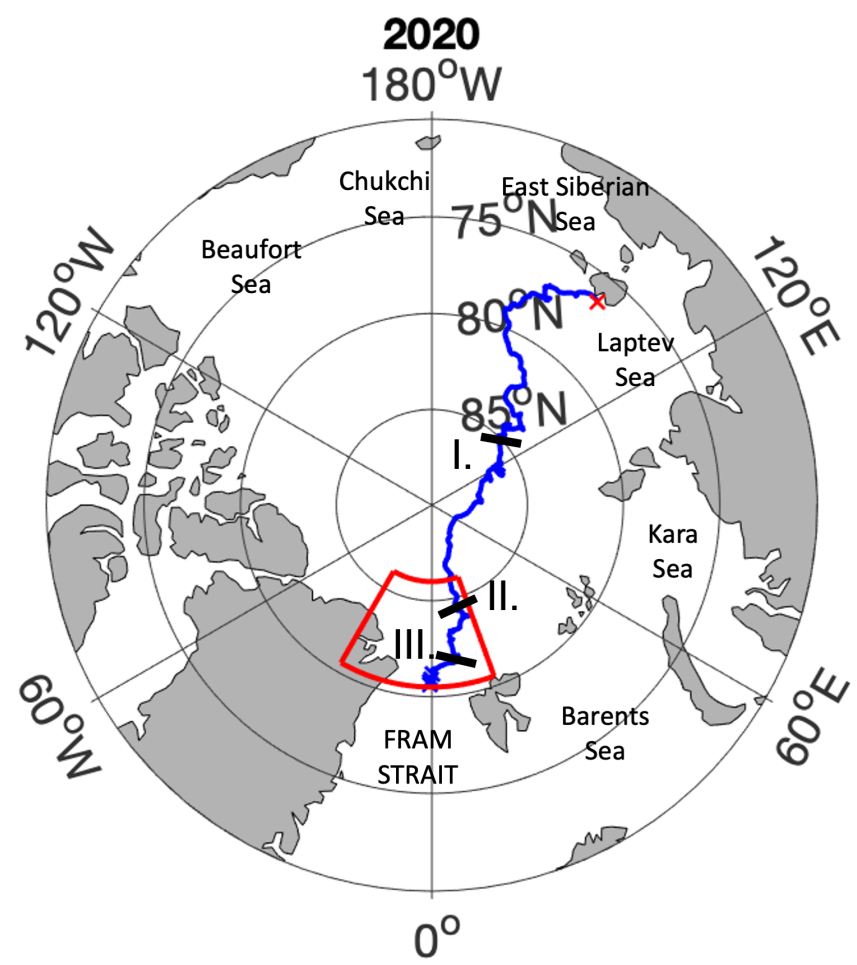

Figure S3. MOSAiC drift trajectory consisting of GPS positions recorded during the drift (from October 4, 2019 until July 21, 2020) and backward tracked position (ICETrack) from the MOSAiC starting point (October 4, 2019) to the position of ice formation (Krumpen et al., 2020). Backward tracking ended when sea ice concentration dropped to $25 \%$ or less, which is defined as the time and location of ice formation (red cross). Start position of the MOSAiC drift (I.), position of airborne EM measurements conducted during Leg 3 (II., see Fig. S4) and Leg 4 (III., see Fig. S5), and the positions of GEM measurements (blue crosses, see Fig. S5) are given as well. Enclosed area (red) indicates the selected area of interest. 


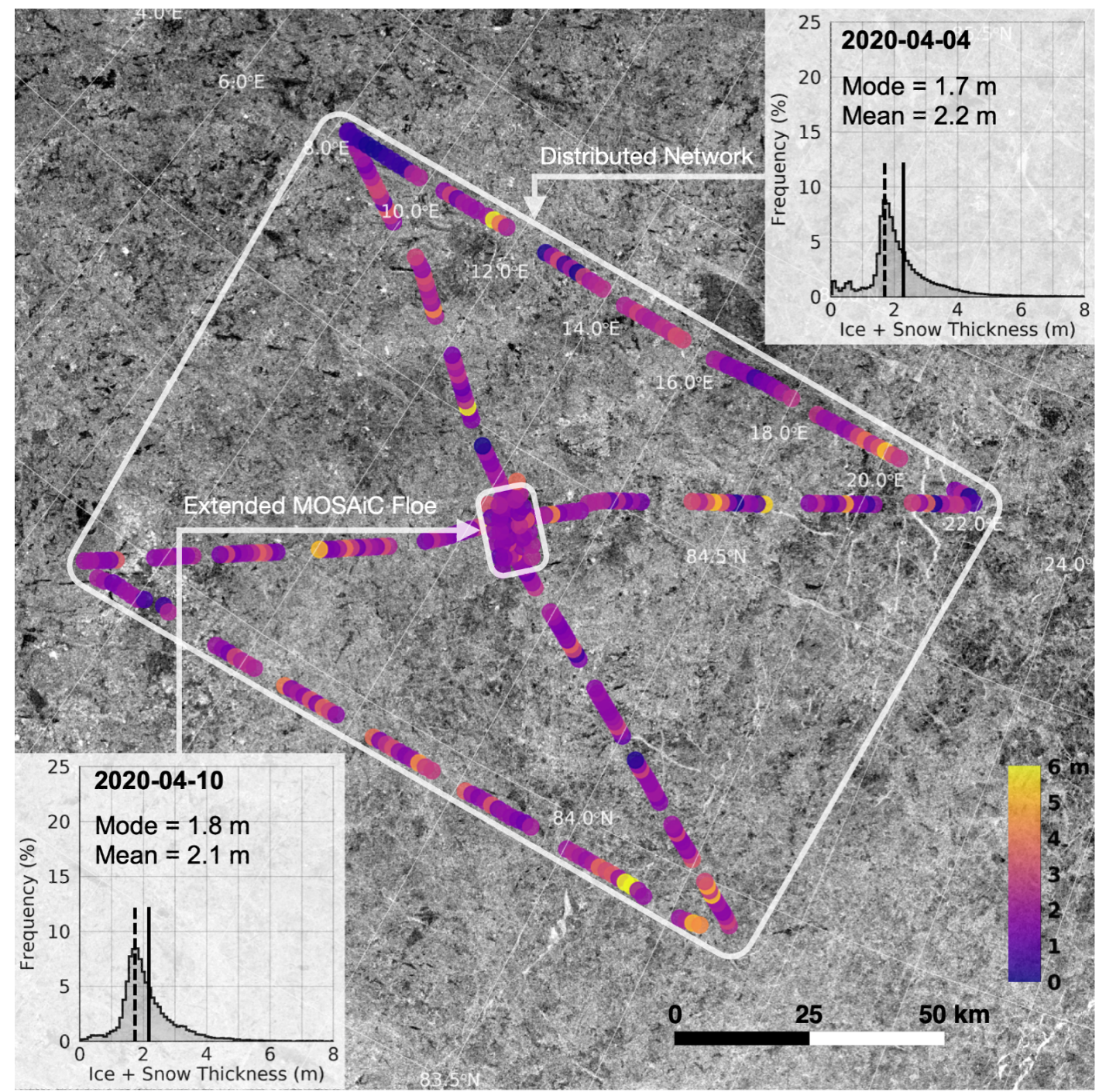

Figure S4. Sentinel-1 SAR image from April 10, 2020 (source: ESA) superimposed by airborne EM survey lines and sea ice thickness (SIT) values gathered during Leg 3 of the Multidisciplinary drifting Observatory for the Study of Arctic Climate (MOSAiC). Modal (dashed) and mean (solid) EM SIT values are given for the extended MOSAiC floe (bottom left) and the larger Distributed Network area (top right). At the time of the survey flights (April 4-10, 2020) the floe was located at approximately $84.5^{\circ} \mathrm{N}$ and $14^{\circ} \mathrm{E}$ (see position II. in Fig. S3). 


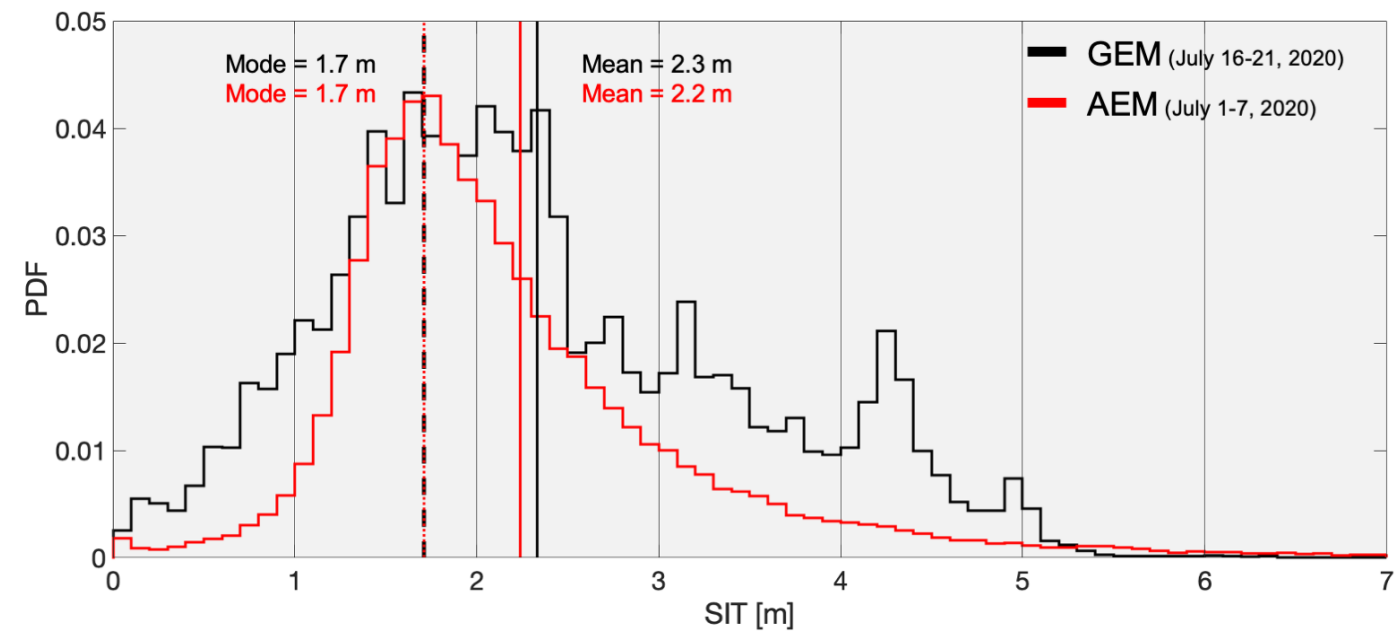

Figure S5. Comparison of MOSAiC floe sea ice thickness distribution gathered with the ground-based EM (GEM) between July 16 to July 21, 2020 (black, see blue crosses in Fig. S3 for position of GEM measurements) and airborne EM (AEM) derived sea ice thickness distribution (red) of the floe and wider area (radius about $5 \mathrm{~km}$ around the floe) from July 1 and July 7, 2020 (see position III. in Fig. S3). Vertical lines indicate distribution mean (solid) and mode (dashed). 